\title{
Characterization of the trypsin-like enzymes of Porphyromonas gingivalis W83 using a radiolabelled active-site-directed inhibitor
}

\author{
Michael A. Curtis, ${ }^{*}$ M. Ramakrishnan and Jennifer M. Slaney \\ MRC Dental Research Unit, 30-32 Newark Street, London Hospital Medical College, Whitechapel, \\ London EI 2AA, UK
}

(Received 25 September 1992; revised 1 December 1992; accepted 14 January 1993)

\begin{abstract}
The trypsin-like enzyme activity of Porphyromonas gingivalis is an important virulence determinant of this organism in destructive periodontitis. An active-site-directed inhibitor, tyrosyl-alanyl-lysyl-arginine chloromethyl ketone (YAKR-CK) was radio-iodinated and used with SDS-PAGE and autoradiography to determine the number and molecular masses of enzymes with trypsin-like specificity produced by $P$. gingivalis W83. Two forms (I \& II) were detected in both crude culture supernatant and whole cell sonicates. Protease I was a sharp band (47 kDa) on reducing SDS-PAGE; Protease II electrophoresed as a diffuse band in the range 70-90 kDa. The specificity with which the inhibitor bound to Protease I was established in competition experiments using other active-sitedirected agents. YAKR-CK inhibited $P$. gingivalis whole cell haemagglutination, supporting the possible role of trypsin-like proteases of this organism in adhesion mechanisms.
\end{abstract}

\section{Introduction}

The anaerobic Gram-negative rod Porphyromonas (formerly Bacteroides) gingivalis is strongly associated with certain forms of periodontitis (destructive inflammatory conditions of the tooth-supporting tissues), particularly adult periodontal disease (Slots, 1982; Slots \& Listgarten, 1988). Compared with quiescent sites, sites in the periodontium which show progressive disease contain elevated numbers of cultivable $P$. gingivalis (Slots et al., 1986), and the serum IgG antibody response to this organism is consistently elevated in cases with a history of destructive disease when compared with controls (Genco \& Slots, 1984; Ebersole et al., 1986; Wilton et al., 1991). However, the precise role of the organism in initiation and progression of the disease is unclear. Analysis of potential virulence determinants of $P$. gingivalis and subsequent interference in their function may help determine which of these components are most closely associated with pathogenesis.

Candidate virulence factors of $P$. gingivalis include its many hydrolytic enzyme activities (Mayrand \& Holt, 1988) and much attention is being directed towards thiolactivated trypsin-like enzyme activity, often used in taxonomy to distinguish $P$. gingivalis from other blackpigmenting species in the subgingival microbial plaque

*Author for correspondence. Tel. (071) 377 0444; fax (071) 247 3428.
(Laughon et al., 1982). Both whole cells and culture supernatant of $P$. gingivalis can hydrolyse and inactivate human plasma proteins involved in the host defence of the periodontal tissues, including immunoglobulins (Sundqvist et al., 1985; Grenier et al., 1989a; Kilian, 1989), iron-binding proteins (Carlsson et al., 1984a) and protease inhibitors (Carlsson et al., 1984b; Nilsson et al., 1985), and this ability correlates with the thiol-activated trypsin-like enzyme activity (Fishburn et al., 1991). Hence this activity is potentially an important virulence determinant of $P$. gingivalis, but its actual importance in the overall virulence of $P$. gingivalis cannot be established until the enzyme(s) in question have been thoroughly characterized.

Trypsin-like enzyme activity is found, using appropriate chromogenic substrates such as nitroanilide derivatives of $\mathrm{C}$-terminal arginyl peptides, in the culture supernatant and associated with whole cells and vesicles of $P$. gingivalis. How many different trypsin-like enzymes are produced by this organism is not known. Many reports in the literature concern the purification or partial purification of supernatant-derived trypsin-like enzymes from different strains of this organism but there is little agreement as yet on either the total number or molecular masses of individual enzymes. For example, using BSA-polyacrylamide conjugate electrophoresis, Grenier et al. (1989b) described the presence of six thiolactivated enzymes with specificity for benzoyl-arginyl- $p$ nitroanilide ranging in molecular mass from 50 to 
$100 \mathrm{kDa}$ in the culture supernatant of $P$. gingivalis. A $300 \mathrm{kDa}$ trypsin-like enzyme was reported by Fujimara \& Nakamura (1987) and a $17 \mathrm{kDa}$ enzyme by Chen et al. (1991). Thiol-activated trypsin-like enzymes with molecular masses between these two extremes have been partially purified by a number of different workers (Yoshimura et al. 1984; Ono et al., 1987; Sorsa et al., 1987; Tsutsui et al., 1987; Uitto et al., 1989).

In the present investigation we sought to label specifically the cell-associated and extracellular trypsinlike enzymes of this organism in order to determine their number and molecular masses. We describe the application of an affinity-labelling technique for trypsinlike protease active sites based on a chloromethyl ketone derivative of radio-iodinated tyrosyl-alanyl-lysyl-arginine.

\section{Methods}

Bacterium and growth conditions. $P$. gingivalis W83, a highly proteolytic strain, was inoculated from a $48 \mathrm{~h}$ horse blood agar plate into brain-heart infusion medium supplemented with $5 \mathrm{mg}$ haemin $\mathrm{l}^{-1}$. The inoculated broths were incubated anaerobically $\left(80 \% \mathrm{~N}_{2}, 10 \%\right.$ $\mathrm{H}_{2}, 10 \% \mathrm{CO}_{2}$, by vol.) for $6 \mathrm{~d}$ at $37^{\circ} \mathrm{C}$.

Enzyme preparations. Extracellular enzyme activity, representing both vesicle-associated and freely soluble enzymes, was harvested by centrifugation $\left(18000 \mathrm{~g}, 30 \mathrm{~min}, 4{ }^{\circ} \mathrm{C}\right)$ of the $6 \mathrm{~d}$ culture. The supernatant fluid was then filter-sterilized ( $0 \cdot 22 \mu \mathrm{M}$ filter) and is referred to throughout the manuscript as crude supernatant. For the preparation of whole cell sonicate, bacterial cells were pelleted by centrifugation and washed once in Tris $/ \mathrm{HCl}(50 \mathrm{~mm}, \mathrm{pH} 7 \cdot 2)$. Following resuspension to $1 / 5 \mathrm{vol}$. in HEPES (10 mM, $\mathrm{pH} 7 \cdot 2)$, they were sonicated on ice for $10 \mathrm{~s}$ periods $(\times 5)$ with intermittent cooling at maximum power using a Soniprep 150 (MSE Scientific Instruments). The sonicate was then centrifuged $\left(40000 \mathrm{~g}, 60 \mathrm{~min}, 4^{\circ} \mathrm{C}\right)$ to remove unbroken cells and cell membranes.

Protease I from crude supernatant was prepared via an isoelectric focussing procedure. Vesicles were precipitated with $40 \%$ saturated ammonium sulphate and discarded. Soluble proteins were precipitated with $70 \%$ saturated ammonium sulphate and then dissolved in, and dialysed against, Tris $/ \mathrm{HCl}(50 \mathrm{~mm}, \mathrm{pH} 7 \cdot 2)$. The dialysate was then made to $1 / 10$ the original culture volume, filter sterilized $(0.22 \mu \mathrm{m}$ pore size) and stored at $-70^{\circ} \mathrm{C}$. Samples of the dialysate were isoelectrically focussed in preparative flatbeds ( $\mathrm{pH} 3 \cdot 5-10$; Application Note 198, LKB Instruments). A trypsin-like enzyme activity, free from contaminating protease activity of differing specificity, was found in fractions of pI 7.5 and pI 4.6 (Harper et al., 1990). The pI 4.6 value, agrees with published estimates for the $\mathrm{pI}$ of a trypsin-like enzyme of this organism (Fujimura \& Nakamura, 1987; Ono et al., 1987), and the corresponding material was therefore dialysed overnight against Tris $/ \mathrm{HCl}$ to remove ampholytes and stored at $-70^{\circ} \mathrm{C}$ until required. This material is referred to throughout as the Protease I preparation.

Protein determinations were done by the method of Simpson \& Sonne (1982) using bovine serum albumin as the standard.

Enzyme assays. Trypsin-like enzyme activity was assessed using the chromogenic substrate Chromozym TRY (Boehringer Mannheim) at $150 \mu \mathrm{M}$ final concentration. Assays were performed in Tris $/ \mathrm{HCl}$ $\left(50 \mathrm{~mm}, \mathrm{pH} 7.2,10 \mathrm{~mm}-\mathrm{CaCl}_{2}, 10 \mathrm{~mm}\right.$-cysteine. $\left.\mathrm{HCl}\right)$, final volume $1.01 \mathrm{ml}$, and the rate of change of absorbance was measured at $405 \mathrm{~nm}$.

The effects of the following inhibitors were examined : tyrosyl-alanyllysyl-arginyl-chloromethyl ketone (YAKR-CK), tosyl-lysyl-chloro- methyl ketone (TLCK), antipain, chymostatin, leupeptin and mercuric chloride. Inhibitor and enzyme preparation were pre-incubated for 15 min prior to addition of the chromogenic substrate and measurements of residual enzyme activity. All experiments were performed in duplicate on at least two separate occasions and the results are presented as mean data. The standard deviations of the means did not exceed $\pm 5 \%$ in each case. Total protease activity was determined by assessment of the rate of degradation of fluorescein-isothiocyanateconjugated bovine serum albumin, using the method of Homer \& Beighton (1990).

Preparation of ${ }^{125}$ I-tyrosine-alanine-lysine-arginine chloromethyl ketone $(Y A K R-C K)$. YAKR-CK was a generous gift from Professor E. Shaw (Friedrich Miescher Institute, Basel, Switzerland). The peptide derivative was radio-iodinated using the method of Fraker \& Speck (1978) using 3,4,6-tetrachloro-3 $\alpha, 6 \alpha$-diphenylglycouril which was dried onto the surface of a $1 \mathrm{ml}$ glass reaction vial from chloroform solution $\left(25 \mu \mathrm{g} \mathrm{ml}^{-1}\right)$. Peptide derivative $\left(50 \mu \mathrm{g}, 1 \mathrm{mg} \mathrm{m}^{-1}\right)$ was radiolabelled in the vial using $5 \mu \mathrm{l}\left[{ }^{125} \mathrm{I}\right]$ sodium iodide $\left(100 \mathrm{mCi} \mathrm{m}^{-1}, 3.7 \mathrm{GBq} \mathrm{ml}^{-1}\right.$, Amersham) for $15 \mathrm{~min}$ before removal to an untreated container. Sodium iodide $(50 \mu \mathrm{l}, 10 \mathrm{~mm})$ was then added and the total reaction mixture was layered on to a Sep-Pack $\mathrm{C}_{18}$ cartridge (Millipore) which had been prewashed with $20 \mathrm{ml}$ acetonitrile followed by $20 \mathrm{ml}$ distilled water. Unbound ${ }^{125}$ I was then eluted with distilled water, and labelled peptide eluted using $50 \%(\mathrm{v} / \mathrm{v})$ acetonitrile in distilled water. The eluted fractions were allowed to evaporate overnight.

Affinity-labelling of $P$. gingivalis enzyme preparations. All labelling procedures were performed in $50 \mathrm{mM}-\mathrm{Tris} / \mathrm{HCl}, \mathrm{pH} 7.4$ (1 mM-Lcysteine, $10 \mathrm{~mm} \mathrm{CaCl}$ ) except where indicated. (A 10-fold lower cysteine concentration than that used in the spectrophotometric enzyme assay was used to reduce the free thiols in the system, which would also react with the chloromethyl ketone.) Crude supernatant, whole cell sonicate or the Protease I preparation was incubated with excess $\left[{ }^{125} \mathrm{I}\right]$ YAKR-CK for $10 \mathrm{~min}$ at room temperature. The samples were then heated at $100^{\circ} \mathrm{C}$ for $5 \mathrm{~min}$ prior to addition of reducing SDS/PAGE sample buffer and further $100^{\circ} \mathrm{C}$ treatment for $10 \mathrm{~min}$. The effect of pretreatment with other active-site-directed inhibitors on the labelling efficiency was examined by preincubation of the appropriate inhibitor with the Protease I preparation for $15 \mathrm{~min}$ prior to addition of the $\left[{ }^{125} \mathrm{I}\right]$ YAKR-CK. SDS-PAGE was performed essentially according to Laemmli (1970) on $10 \%(\mathrm{w} / \mathrm{v})$ acrylamide/ bisacrylamide separating gels incorporating a $4 \%(\mathrm{w} / \mathrm{v})$ stacking gel, and proteins were visualized using Coomassie blue. Autoradiography of dried, stained gels was performed using Hyperfilm-ECL (Amersham).

Haemagglutination assay. Haemagglutinating activity was assayed using washed normal human red blood cells in complement fixation diluent (CFD, Oxoid). Bacterial suspensions were washed three times in CFD, and resuspended to $A_{640}=1 \cdot 0$. Doubling dilutions of bacterial suspension or the Protease I preparation were made in CFD from $1 / 2-1 / 256$ in a total volume of $50 \mu \mathrm{l}$ in $96-$ well microtitre plates. To each well, a further $50 \mu \mathrm{l} \mathrm{CFD}$ and $50 \mu 10.5 \%$ human red blood cells were added, and the plates were incubated at room temperature for $2 \mathrm{~h}$. When an agglutinating titre had been established, the effect of a range of protease inhibitors was examined. Solutions of each inhibitor were double-diluted in CFD and incubated with four times the minimum haemagglutinating dose of Protease I or bacterial suspension for $20 \mathrm{~min}$ at room temperature. Human red blood cells were added and incubation continued for a further $2 \mathrm{~h}$.

\section{Results and Discussion}

The concept of affinity labelling was first demonstrated by active-site alkylation of the His- 57 in chymotrypsin by 


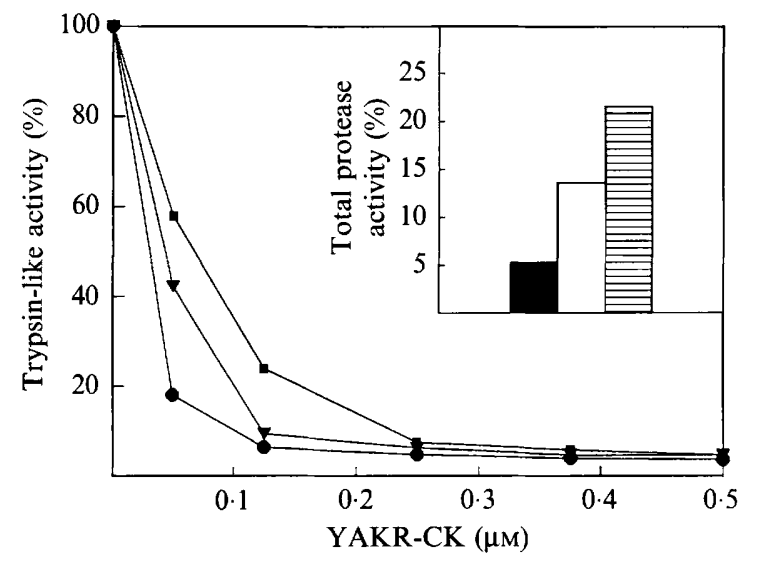

Fig. 1. Effect of YAKR-CK on trypsin-like enzyme activity of crude supernatant $(\boldsymbol{\square})$, cell sonicate $(\boldsymbol{O})$ and the Protease I preparation $(\boldsymbol{\nabla})$ from the crude supernatant of $P$. gingivalis W83. Insert shows the \% residual total protease activity in each preparation following treatment with $5 \mu \mathrm{M}$-YAKR-CK, measured using FITC-BSA: Protease I, solid bar; cell sonicate, open bar; culture supernatant, hatched bar.

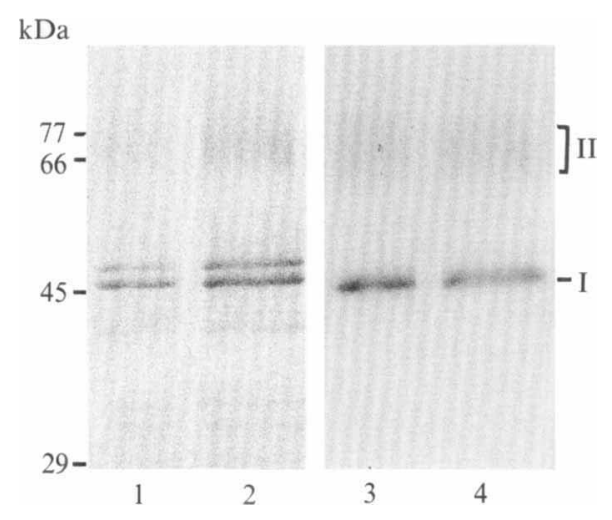

Fig. 2. Affinity labelling of the trypsin-like enzymes in crude supernatant $P$. gingivalis W83 using ${ }^{125} \mathrm{I}-$ YAKR-CK. Lanes 1 and 2 , Coomassie-blue-stained SDS-PAGE gel of 2.5 and $5.0 \mu \mathrm{g}$ crude supernatant protein pretreated with labelled inhibitor; lanes 3 and 4 , autoradiogram of lanes 1 and 2. Numbers in left margin refer to positions of molecular mass markers: ovotransferrin ( $77 \mathrm{kDa})$; albumin (66 kDa); ovalbumin (45 kDa); carbonic anhydrase (29 kDa). 1 and II, bands discussed in text.

a chloromethyl ketone (Tos-Phe- $\mathrm{CH}_{2} \mathrm{Cl}$ ), an alkylating derivative of a good substrate for this enzyme (Schoellmann \& Shaw, 1973; Singh et al., 1962; Shaw, 1970). We had observed that all the trypsin-like enzyme activity of crude culture supernatant and whole cell sonicates of $P$. gingivalis was fully inhibited by certain chloromethyl ketone derivatives of substrates of trypsin-like enzymes, particularly TLCK. This led us to reason that the use of a radio-labelled chloromethyl ketone derivative of a peptide, preferably with a C-terminal arginine or lysine residue, would be a suitable reagent for affinity-labelling all the trypsin-like enzymes of $P$. gingivalis. Coupled to SDS-PAGE and autoradiography, this would then allow us to quantify each enzyme and determine molecular mass. An identical procedure had been employed for the demonstration of multiple trypsin-like proteases in rat islets of Langerhans using YAKR-CK, in which the tyrosine residue proved an ideal vehicle for radioiodination (Docherty, 1982). The trypsin-like enzyme activity in crude supernatants and whole cell sonicates of $P$. gingivalis $\mathrm{W} 83$, adjusted to the same initial activity, was abolished by YAKR-CK (Fig. 1), demonstrating the suitability of this reagent for the quantification of these enzymes. However, although this inhibitor was effective against the trypsin-like activity, based on the synthetic chromogenic substrate assay, the total protease assay using FITC-BSA demonstrated that a proportion of the proteolytic enzyme activity was still active in the crude preparations $(22 \%$ for crude supernatant and $14 \%$ for sonicated whole cells) following treatment with excess YAKR-CK (Fig. 1, inset). The trypsin-like activity and total protease activity of the Protease I preparation were both reduced to $<5 \%$ following treatment with excess YAKR-CK. Thus non-trypsin-like enzyme(s) contribute to the total protease activity of this organism.

\section{Affinity labelling of $P$. gingivalis W83 culture supernatant, cell sonicates and $47 \mathrm{kDa}$ enzyme preparation}

Autoradiograms of SDS-PAGE gels of crude supernatant labelled with [ ${ }^{125}$ I]YAKR-CK demonstrated two distinct activities in the total extracellular fraction (Fig. 2). First, a well defined band with a mobility corresponding to a molecular mass of about $47 \mathrm{kDa}$ (labelled I in Fig. 2). This coincided in position with a major protein on Coomassie-blue-stained gels of culture supernatant (lanes $1 \& 2$, Fig. 2). The specificity of the labelling procedure was demonstrated by the absence of radioactivity associated with a protein of slightly higher molecular mass and similar staining intensity to the $47 \mathrm{kDa}$ protein on the Coomassie-blue-stained gel. A second, less intense, and very diffuse activity was located in the $70-90 \mathrm{kDa}$ area of the gel (labelled II in Fig. 2). Repeated attempts to improve the resolution of this band were unsuccessful. The reason for the poor electrophoretic behaviour of this species is unknown at present. Possible explanations may involve either high concentrations of associated carbohydrate or autolysis prior to inactivation. Sonicates of whole cells showed a similar pattern of labelling with YAKR-CK, although the relative proportion of Protease II in these preparations appeared higher than in culture supernatant (Fig. 3). SDS-PAGE analysis of the Protease I preparation demonstrated a predominant $47 \mathrm{kDa}$ component, with small amounts of 43,40 and $30 \mathrm{kDa}$ contaminant proteins. Autoradiography of $\left[{ }^{125} \mathrm{I}\right] \mathrm{YAKR}-\mathrm{CK}$-treated 


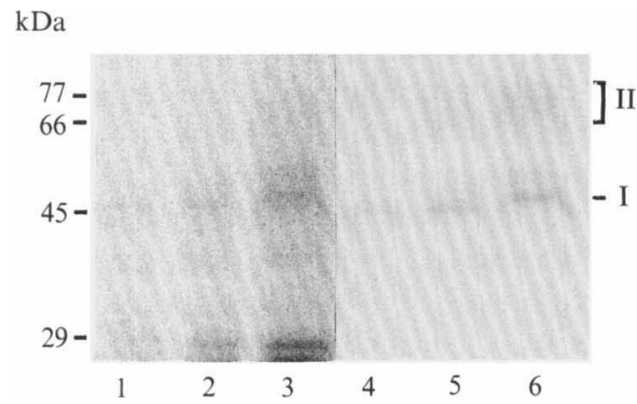

Fig. 3. Affinity labelling of the trypsin-like enzymes in whole cell sonicates of $P$. gingivalis W83 using ${ }^{125} \mathrm{I}-$ YAKR-CK. Lanes: $1-3$, Coomassie-blue-stained SDS-PAGE of sonicated whole cells $(0 \cdot 8,1 \cdot 6$ and $4 \mu \mathrm{g}$ protein, respectively) pretreated with labelled inhibitor; 4-6, autoradiogram of lanes 1-3. I and II, bands discussed in text.

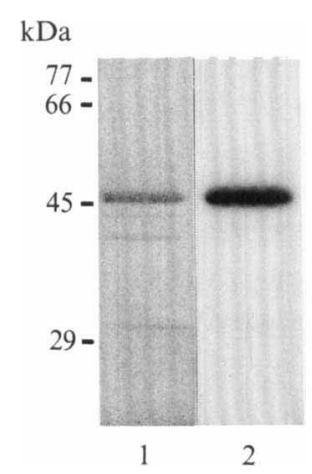

Fig. 4. Affinity labelling of an iso-electric-focussing preparation of Protease $I$ of $P$. gingivalis W83 using ${ }^{125} \mathrm{I}-\mathrm{YAKR}-\mathrm{CK}$. Lane 1 , Coomassie-blue-stained SDS-PAGE gel of enzyme $(0.5 \mu \mathrm{g})$ pretreated with labelled inhibitor; lane 2, autoradiogram of lane 1 .

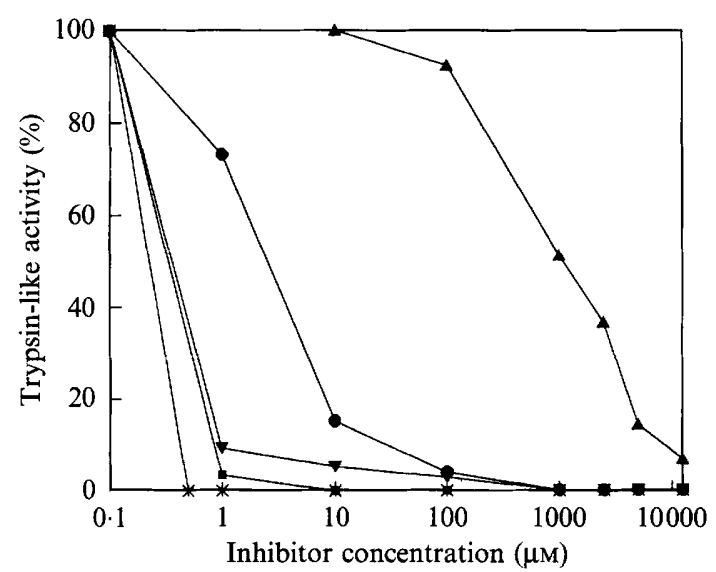

Fig. 5. Effect of active-site-directed inhibitors on the trypsin-like enzyme activity of Protease I: $\times$, YAKR-CK; $\boldsymbol{\square}$, antipain; $\boldsymbol{\bullet}$, chymostatin; $\boldsymbol{\nabla}$, TLCK; $\boldsymbol{\Delta}, \mathrm{HgCl}_{2}$.

Protease I preparation gave a single strong band at $47 \mathrm{kDa}$, indicating the separation of Protease I from Protease II by the iso-electric focussing procedure (Fig. 4). This material was then used to examine the specificity and blocking of YAKR-CK-binding to Protease I.
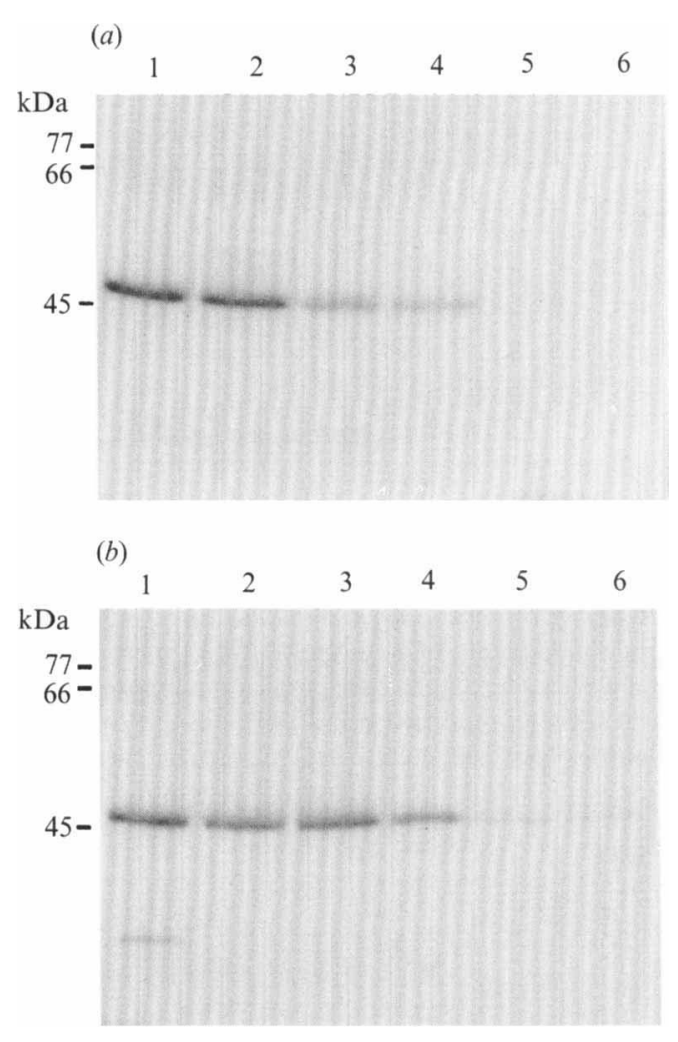

Fig. 6. Effect of protease inhibitors on ${ }^{125}$ I-YAKR-CK labelling of Protease I $(0.5 \mu \mathrm{g})$. The enzyme was pretreated with each of the inhibitors/modifiers for $15 \mathrm{~min}$ prior to labelling with ${ }^{125}$ I-YAKR. (a) Lanes: 1 , L-cysteine $(10 \mathrm{~mm}) ; 2$, Tris $/ \mathrm{HCl}, \mathrm{pH} 7.2(50 \mathrm{mM}) ; 3$ and 4 , $\mathrm{HgCl}_{2}$ (5 and $\left.25 \mathrm{~mm}\right) ; 5$ and 6, TLCK $(0.01$ and $1.0 \mathrm{~mm}) .(b)$ Lanes: 1 , L-cysteine $(10 \mathrm{mM}) ; 2$ and 3 , chymostatin $(0.01$ and $1.0 \mathrm{~mm}) ; 4$ and 5 , antipain $(0.01$ and $1.0 \mathrm{~mm}) ; 6$, heat-inactivated enzyme $\left(100^{\circ} \mathrm{C}\right.$, $10 \mathrm{~min})$.

\section{Inhibitors of YAKR-CK-labelling of Protease I}

The specificity of binding of YAKR-CK to Protease I was examined by preincubation of the enzyme with other inhibitors which interact with the active site of serine/ cysteine enzymes. Antipain and chymostatin are peptide aldehydes which inhibit members of both classes of enzyme through the formation of a hemiacetal or hemithio-acetal linkages between the aldehyde carbonyl of the inhibitor and the active site serine or cysteine of the enzyme. Both of these aldehyde peptides inhibited the hydrolysis of Chromozym TRY by Protease I (Fig. 5). The apparent discrepancy in the effectiveness of the two inhibitors most likely reflects the relative purity/ activity of these two commercial preparations rather than absolute differences in the stoichiometry of the respective interactions. Preincubation of the Protease I preparation with these inhibitors, at concentrations which achieved full enzyme inhibition, eliminated the binding of YAKR-CK to the enzyme (Fig. $6 a$ ), indicating the requirement for an unblocked serine/cysteine 
active site residue for YAKR-CK binding. Similarly, TLCK which shares the same mechanism of inhibition as YAKR-CK, inhibited enzyme activity and blocked the binding of the radiolabelled inhibitor (Figs 5 and $6 b$ ).

In an attempt to probe the identity of the nucleophilic residue at the active site of Protease I, we examined the binding of YAKR-CK in the presence and absence of activating concentrations of thiol groups in the buffer and of mercuric ions, which inhibit cysteine enzymes through non-specific interaction with free thiol groups on the protein. No hydrolysis of Chromozym TRY by Protease I was observed in the absence of exogenously added thiols. Maximal activity was obtained at cysteine. $\mathrm{HCl}$ concentrations greater than $1 \mathrm{~mm}$ (data not shown). This is in agreement with several reports in the literature on the thiol-activated nature of the trypsin-like enzyme activity of this organism. However, absence of cysteine in the labelling buffer had no effect on the binding of YAKR-CK to the enzyme (Fig. 6b). An incidental finding upon inclusion of cysteine was the occasional generation of a minor component of lower molecular mass which was also labelled with YAKR-CK (Fig. $6 b$, lane 1). An explanation for the appearance of this component may be the autolytic modification of Protease $I$ in the presence of activating concentrations of thiol residues prior to full inhibition by YAKR-CK. Autolytic degradation of the trypsin-like proteases of this organism may account for the multiple molecular masses reported for these enzymes (Grenier et al., 1989 b). Mercuric ions, above $10 \mathrm{~mm}$, fully inhibited Protease I in the chromogenic substrate assay but only partially reduced the binding of YAKR-CK when present at $25 \mathrm{~mm}$. This discrepancy may be explained by the mercuric ion inhibition in the enzyme assay being a result of the consumption of free thiols from the buffer rather than reaction with an active site cysteine residue, which would be expected to cause a concomitant inhibition of labelling with YAKR-CK. Alternatively, inhibition of activity by mercuric ions may be mediated through reaction with a cysteine residue not directly involved in the catalytic process: there are some members of the subtilisin family of serine proteases which have a free -SH group, apparently not catalytically functional, whose reaction with mercury causes inactivation, possibly because of proximity to essential residues (Betzel et al., 1986; Mizuno et al., 1988). Shah et al. (1991) have isolated a cysteine protease from $P$. gingivalis, although a full characterization of the enzyme has not been reported. However on the basis of an approximate molecular mass of $95-100 \mathrm{kDa}$, it appears to be distinct from Protease I and II in the present report. Unequivocal classification of Protease I must await determination of the primary sequence of the active site residues. However, use of YAKR-CK may permit a more targetted approach to
Table 1. Minimum inhibitory concentration of inhibitors of agglutination of human red blood cells by $P$. gingivalis whole cells and Protease I

Numbers in parentheses refer to maximum concentration used.

\begin{tabular}{lll}
\hline & \multicolumn{2}{c}{ Minimum inhibitory concn (mM) for: } \\
\cline { 2 - 3 } Inhibitor & \multicolumn{1}{c}{ Whole cells } & Protease I \\
\hline YAKR-CK & $<0 \cdot 002$ & $0 \cdot 25$ \\
$\mathrm{HgCl}_{2}$ & nil $(12 \cdot 5)$ & nil $(12 \cdot 5)$ \\
TLCK & $0 \cdot 13$ & $<0 \cdot 040$ \\
Chymostatin & nil $(0 \cdot 4)$ & nil $(0 \cdot 4)$ \\
Antipain & nil $(0 \cdot 25)$ & nil $(0 \cdot 25)$ \\
\hline
\end{tabular}

this analysis via $\mathrm{N}$-terminal sequence analysis of peptide maps of the labelled enzyme.

\section{Inhibition of haemagglutination}

There is increasing evidence that the trypsin-like enzyme activities have a role in the adherence of $P$. gingivalis to a variety of surfaces in the sub-gingival environment. Attachment of $P$. gingivalis whole cells to collagenous substrata (Naito \& Gibbons, 1988) and haemagglutination of human red blood cells by this organism (Inoshita et al., 1986; Okuda et al., 1986) are both blocked by protease inhibitors, and the co-aggregation of $P$. gingivalis with Actinomyces viscosus is similarly disrupted by agents capable of inhibiting the cellassociated trypsin-like enzyme activity (Li et al., 1991). In the current investigation, the Protease I preparation was able to agglutinate human red blood cells, and this was inhibited by YAKR-CK (Table 1). Although other minor protein components are present in this preparation, YAKR-CK bound only to the $47 \mathrm{kDa}$ moiety and hence it is reasonable to conclude that the protease itself is involved in the haemagglutination reaction. Haemagglutination was also inhibited by TLCK, but not by chymostatin nor antipain, both of which could fully inhibit Chromozym TRY hydrolysis at much lower concentrations (Fig. 5). Similar data were obtained using $P$. gingivalis whole cells. The discrepancy between the data for inhibition of haemagglutination compared to those for inhibition of protease activity indicates that simply blocking of the active site of the protease may be insufficient to prevent binding to the erythrocyte membrane surface: other sub-sites on the molecule may be involved, or the haemagglutinating molecule may represent a multicomponent system incorporating a proteolytic element(s) and adhesion polypeptide(s). The present data do not therefore enable the distinction between (1) a direct role for the trypsin-like proteases of this organism in haemagglutination via binding to the 
erythrocyte surface through the active site(s), and (2) an indirect role via proteolytic unmasking of epitopes which may act as targets for $P$. gingivalis adhesins on the erythrocyte membrane.

We conclude that $P$. gingivalis W83 expresses two distinct proteases with trypsin-like specificity. Both enzymes are cell-associated and released into the supernatant of batch cultures of the organism. We cannot yet state whether they are both components of the extracellular vesicle trypsin-like activity (Smalley \& Birss, 1987). These data are complementary to those recently presented by Hinode et al. (1991) who described the purification of three proteases from the culture supernatant of $P$. gingivalis 381. Two of these were active against benzoyl-arginyl-p-nitroanilide and had similar electrophoretic mobilities on SDS-PAGE to Proteases I and II as described in this investigation. Given the wide disparity of molecular masses in the literature for the trypsin-like enzymes produced by this organism, it is possible that the enzymes exist in polymeric forms and/or undergo proteolytic modification when in solution. However, the relative ease of separation of the two activities in culture supernatant by iso-electric focussing suggests that they do not co-polymerize. The extent of monomer association and autolysis is currently under investigation.

\section{References}

Betzel, C., Pal, G. P., Struck, M., Jany, K.-D. \& Saenger, W. (1986). Active-site geometry of proteinase K. Crystallographic study of its complex with a dipeptide chloromethyl ketone inhibitor. FEBS Letters 197, 105-110.

Carlsson, J., Hoflung, J. F. \& Sundevist, G. K. (1984a). Degradation of albumin, haemopexin, haptoglobin and transferrin by black-pigmented Bacteroides species. Journal of Medical Microbiology 18, 39-46.

Carlsson, J., Herrman, B. F., Hoflung, J. F. \& Sundquist, G. K. $(1984 b)$. Degradation of the human proteinase inhibitors alpha-1 antitrypsin and alpha-2 macroglobulin by Bacteroides gingivalis. Infection and Immunity 43, 644-648.

Chen, Z., Potempa, J., Polanowski, A., Renvert, S., Wikstrom, M. \& TRAVIS, J. (1991). Stimulation of proteinase and amidase activities in Porphyromonas (Bacteroides) gingivalis by amino acids and dipeptides. Infection and Immunity 59, 2846-2850.

Docherty, K., Carroll, R. J. \& Steiner, D. F. (1982). Conversion of proinsulin to insulin: Involvement of a 31,500 molecular weight thiol protease. Proceedings of the National Academy of Sciences of the United States of America 79, 4613-4617.

Ebersole, J. L., Taubman, M. A., Smith, D. J. \& Frey, D. E. (1986). Human immune responses to oral microorganisms: patterns of systemic antibody levels to Bacteroides species. Infection and Immunity 51, 507-513.

Fishburn, S., Slaney, J. M., Carman, R. J. \& Curtis, M. A. (1991). Degradation of plasma proteins by the trypsin-like enzyme of $P$. gingivalis and inhibition of protease activity by a serine protease inhibitor of human plasma. Oral Microbiology and Immunology $\mathbf{6}$, 209-215.

FrakeR, P. J. \& SPECK, J. C. (1978). Protein and cell membrane iodinations with a sparingly soluble chloroamide, 1,3,4,6-tetrachloro $3 \alpha, 6 \alpha$-diphenylglycouril. Biochemical and Biophysical Research Communications 80, 84-89.
FUJimaRA, S. \& NAKAMURA, T. (1987). Isolation and characterization of a protease from Bacteroides gingivalis. Infection and Immunity $\mathbf{5 5}$, 716-720.

Fujimara, S. \& NaKamura, T. (1989). Multiple forms of proteases of Bacteroides gingivalis and their cellular location. Oral Microbiology and Immunology 4, 227-229.

Genco, R. J. \& Slots, J. (1984). Host responses in periodontal disease. Journal of Dental Research 63, 441-451.

Grenier, D., MaYrand, D. \& McBride, B. C. (1989a). Further studies on the degradation of immunoglobulins by black-pigmented Bacteroides. Oral Microbiology and Immunology 4, 12-18.

GreniER, D., ChaO, G. \& MCBrIDE, B. C. (1989 $b$ ). Characterization of sodium dodecyl sulphate-stable proteases by polyacrylamide gel electrophoresis. Infection and Immunity 57, 95-99.

Harper, F. H., Duncan, A. J., Beighton, D. \& Carman, R. J. (1990). Porphyromonas (Bacteroides) gingivalis W83: Partial purification and characterisation of a protease from culture supernatant fluid. In Clinical and Molecular Aspects of Anaerobes, pp. 175. Edited by S. P. Borriello. Petersfield: Wrightson Biomedical.

Hinode, D., Hayashi, H. \& Nakamura, R. (1991). Purification and characterization of three types of proteases from culture supernatants of Porphyromonas gingivalis. Infection and Immunity 59, 3060-3068.

HOMER, K. A. \& BeIGHTON, D. (1990). Fluorometric determination of bacterial protease activity using fluorescein isothiocyanate-labelled proteins as substrates. Analytical Biochemistry 191, 133-137.

inoshita, E., Amano, A., Hanioka, T., Tamagawa, H., Shizukuishi, S. \& TSUNEMITSU, A. (1986). Isolation and some properties of exohemagglutinin from culture medium of Bacteroides gingivalis 381 . Infection and Immunity 52, 421-427.

KILIAN, M. (1989). Degradation of immunoglobulins A1, A2 and G by suspected periodontal pathogens. Infection and Immunity 57, 18681871.

LAEMmLI, U. K. (1970). Cleavage of the structural proteins during the assembly of the head of bacteriophage T4. Nature, London 227, 680-685.

Laughon, B. E., Syed, S. A. \& Loesche, W. J. (1982). Rapid identification of Bacteroides gingivalis. Journal of Clinical Microbiology 15, 345-346.

Li, J., Ellen, R. P., Hoover, C. I. \& Felton, J. R. (1991). Association of proteases of $P$. gingivalis with its adhesion to Actinomyces viscosus. Journal of Dental Research 70, 82-86.

MAYRAND, D. \& HolT, S. C. (1988). Biology of asaccharolytic blackpigmented Bacteroides species. Microbiological Reviews 52, 134-152.

Mizuno, K., Nakamura, T., Ohshima, T., Tanaka, S. \& Matsuo, $H$. (1988). Yeast KEX2 gene encodes an endopeptidase homologous to subtilisin-like serine proteases. Biochemical and Biophysical Research Communications 156, 246-254.

NaIto, Y. \& GiBBons, R. J. (1988). Attachment of Bacteroides gingivalis to collagenous substrata. Journal of Dental Research 67, 1075-1080.

NilsSON, T., CARLsSON, J. \& SUNDQvisT, G. (1985). Inactivation of key factors of the plasma proteinase cascade systems by Bacteroides gingivalis. Infection and Immunity 50, 467-471.

OKuda, K., Yamamoto, A., Naito, Y., Takazoe, I., Slots, J. \& GeNCo, R. J. (1986). Purification and properties of hemagglutinin from culture supernatant of Bacteroides gingivalis. Infection and Immunity 54, 659-665.

Ono, M., OKUda, K. \& TaKazoe, I. (1987). Purification and characterisation of a thiol-protease from Bacteroides gingivalis strain 381. Oral Microbiology and Immunology 2, 77-81.

Otsuka, M., Endo, J., Hinode, D., Nagata, A., Maehara, R., Sato, M. \& NaKAMURA, T. (1987). Isolation and characterisation of protease from culture supernatant of Bacteroides gingivalis. Journal of Periodontal Research 22, 491-498.

SchollmanN, G. \& ShaW, E. (1963). Direct evidence for the presence of histidine in the active center of chymotrypsin. Biochemistry $\mathbf{2}$, 252-255.

Shah, H. N., Gharbia, S. E., Kowlessur, D., Wilkie, E. \& BrockleHURST, K. (1991). Gingivain; a cysteine proteinase isolated from Porphyromonas gingivalis. Microbial Ecology in Health and Disease 4, 319-328.

SHaw, E. (1970). Chemical modification by active-site-directed re- 
agents. In The Enzymes, pp. 91-147. Edited by P. D. Boyer. New York: Academic Press.

Simpson, I. A. \& SonNe, O. (1982). A simple, rapid and sensitive method for measuring protein concentration in subcellular membrane fractions prepared by sucrose density ultracentrifugation. Analytical Biochemistry 119, 424427.

Singh, A., Thornton, E. \& Westheimer, F. H. (1962). The photolysis of diazo-acetylchymotrypsin. Journal of Biological Chemistry 237, 3006-3008.

SLoTs, J. (1982). Importance of black pigmented Bacteroides in human periodontal disease. In Host-Parasite Interactions in Periodontal Diseases, pp. 27-45. Edited by R. J. Genco \& S. E. Mergenhagen. Washington DC: American Society for Microbiology.

Slots, J. \& ListgarTeN, M. A. (1988). Bacteroides gingivalis, Bacteroides intermedius and Actinobacillus actinomycetemcomitans in human periodontal diseases. Journal of Clinical Periodontology 15, $85-93$.

Slots, J., Bragd, L., Wikstron, M. \& Dahlen, G. (1986). The occurrence of Actinobacillus actinomycetemcomitans, Bacteroides gingivalis and Bacteroides intermedius in destructive periodontal disease in adults. Journal of Clinical Periodontology 13, 576-577.

Smalley, J. W. \& Birss, A. J. (1987). Trypsin-like enzyme activity of the extracellular membrane vesicles of Bacteroides gingivalis W50. Journal of General Microbiology 133, 2883-2894.
Sorsa, T., Uito, V.-J., Suomalainen, K., Turto, H. \& Lindy, S. (1987). A trypsin-like protease from Bacteroides gingivalis: partial purification and characterisation. Journal of Periodontal Research 22, 375-380.

Sundqvist, G., Carlsson, J., Herrmann, B. \& Tarnvik, A. (1985). Degradation of human immunoglobulins $\mathrm{G}$ and $\mathrm{M}$ and complement factors C3 and C5 by black-pigmented Bacteroides. Journal of Medical Microbiology 19, 85-94.

Tsutsui, H., Kinouchi, T., Wakano, Y. \& Ohnishi, Y. (1987). Purification and characterisation of a protease from Bacteroides gingivalis 381. Infection and Immunity 55, 420-427.

Uitto, V.-J., LaRjaVa, H., Heino, J. \& Sorsa, T. (1989). A protease of Bacteroides gingivalis degrades cell surface and matrix glycoproteins of cultured gingival fibroblasts and induces secretion of collagenase and plasminogen activator. Infection and Immunity 57, 213-218.

Wilton, J. M. A., Johnson, N. W., Curtis, M. A., Gillette, I. R. Carman, R. J., Bampton, J. L. M., Griffiths, G. S. \& Sterne, J. A. C. (1991). Specific antibody responses to subgingival plaque bacteria as aids to the diagnosis of destructive periodontitis. Journal of Clinical Periodontology 18, 1-15.

Yoshimura, F., Nishikata, M., Susuki, T., Hoover, C. I. \& Newbrun, E. (1984). Characterization of a trypsin-like protease from the bacterium Bacteroides gingivalis isolated from human dental plaque. Archives of Oral Biology 29, 559-564. 